\title{
Pancreatic cancer as a sentinel for hereditary cancer predisposition
}

\author{
Erin L. Young ${ }^{1}$, Bryony A. Thompson ${ }^{2,3}$, Deborah W. Neklason ${ }^{2,4}$, Matthew A. Firpo ${ }^{2,5}$, Theresa Werner ${ }^{2,6}$, \\ Russell Bell1', Justin Berger ${ }^{7}$, Alison Fraser ${ }^{7}$, Amanda Gammon², Cathryn Koptiuch², Wendy K. Kohlmann², \\ Leigh Neumayer $^{8}$, David E. Goldgar ${ }^{2,9}$, Sean J. Mulvihill ${ }^{2,5}$, Lisa A. Cannon-Albright ${ }^{2,4,10}$ and Sean V. Tavtigian ${ }^{1,2^{*}}$ (D)
}

\begin{abstract}
Background: Genes associated with hereditary breast and ovarian cancer (HBOC) and colorectal cancer (CRC) predisposition have been shown to play a role in pancreatic cancer susceptibility. Growing evidence suggests that pancreatic cancer may be useful as a sentinel cancer to identify families that could benefit from HBOC or CRC surveillance, but to date pancreatic cancer is only considered an indication for genetic testing in the context of additional family history.

Methods: Preliminary data generated at the Huntsman Cancer Hospital $(\mathrm{HCH})$ included variants identified on a custom 34-gene panel or 59-gene panel including both known HBOC and CRC genes for respective sets of 66 and 147 pancreatic cancer cases, unselected for family history. Given the strength of preliminary data and corresponding literature, 61 sequential pancreatic cancer cases underwent a custom 14-gene clinical panel. Sequencing data from $\mathrm{HCH}$ pancreatic cancer cases, pancreatic cancer cases of the Cancer Genome Atlas (TCGA), and an unselected pancreatic cancer screen from the Mayo Clinic were combined in a meta-analysis to estimate the proportion of carriers with pathogenic and high probability of pathogenic variants of uncertain significance (HiP-VUS).

Results: Approximately $8.6 \%$ of unselected pancreatic cancer cases at the $\mathrm{HCH}$ carried a variant with potential $\mathrm{HBOC}$ or CRC screening recommendations. A meta-analysis of unselected pancreatic cancer cases revealed that approximately $11.5 \%$ carry a pathogenic variant or HiP-VUS.

Conclusion: With the inclusion of both $\mathrm{HBOC}$ and CRC susceptibility genes in a panel test, unselected pancreatic cancer cases act as a useful sentinel cancer to identify asymptomatic at-risk relatives who could benefit from relevant $\mathrm{HBOC}$ and $\mathrm{CRC}$ surveillance measures.
\end{abstract}

Keywords: HBOC, Lynch syndrome, Colorectal cancer, Pancreatic cancer, Genetic testing

\section{Background}

Over the last few years, massively parallel sequencing converged with targeted capture using array synthesized baits to enable panel testing of most known cancer susceptibility genes [1-4]. These panel tests have since replaced Sanger sequencing of limited sets of syndromic genes, thereby revolutionizing the genetic testing landscape for Hereditary Breast and Ovarian cancer (HBOC) and Colorectal cancer (CRC) predisposition. A great

\footnotetext{
* Correspondence: sean.tavtigian@hci.utah.edu

'Department of Oncological Sciences, University of Utah School of Medicine, Salt Lake City, United States

${ }^{2}$ Huntsman Cancer Institute, University of Utah School of Medicine, Salt Lake City, United States

Full list of author information is available at the end of the article
}

benefit for these predictive genetic tests is to identify carriers of pathogenic medically-actionable variants in asymptomatic individuals, notably the at-risk relatives of the sentinel cancer patient.

Methods for prevention or early detection of pancreatic cancer have limited utility, $[5,6]$ so utilizing germline predisposition testing to identify individuals with modest to moderate increases in pancreatic cancer susceptibility is also limited in utility. Current guidelines recommend genetic testing only in pancreatic cancer patients with additional family history matching the patterns indicative of hereditary breast and ovarian cancer, colorectal cancer predisposition such as FAP or Lynch syndrome, or melanoma [7-11]. However, studies have

(c) The Author(s). 2018 Open Access This article is distributed under the terms of the Creative Commons Attribution 4.0 International License (http://creativecommons.org/licenses/by/4.0/), which permits unrestricted use, distribution, and reproduction in any medium, provided you give appropriate credit to the original author(s) and the source, provide a link to the Creative Commons license, and indicate if changes were made. The Creative Commons Public Domain Dedication waiver (http://creativecommons.org/publicdomain/zero/1.0/) applies to the data made available in this article, unless otherwise stated. 
found that these criteria will miss $50 \%$ of pancreatic cancer patients who harbor actionable pathogenic variants $[12,13]$. Therefore, pancreatic cancer may be a useful sentinel cancer for identification of carriers of pathogenic variants in $\mathrm{HBOC}$ and CRC susceptibility genes, whose relatives can benefit from surveillance, medical, and surgical strategies for prevention, risk reduction, or early detection [7, 14-22].

To estimate the percentage of pancreatic cancer cases that carry variants with potential medical management impact for at-risk relatives, we applied panel testing to 274 pancreatic cancer patients ascertained at the Huntsman Cancer Hospital $(\mathrm{HCH})$ in Salt Lake City, UT, unselected for family cancer history. To demonstrate generalizability of the results in pancreatic cancer cases, we performed a meta-analysis including published panel tests of unselected pancreatic cancer cases.

\section{Methods}

\section{Subjects and ethics statement}

This study was approved by the Institutional Review Board of the University of Utah. All participants gave written consent, which included DNA sampling for molecular studies and access to medical records.

An initial set of pancreatic cancer cases $(n=66)$ were selected on the minimal requirements of personal history of cancer and having at least two grandparents in the genealogy data represented in the Utah Population Database (UPDB). These patients were screened with a 34-gene custom research panel. Individual family members were then linked to statewide cancer, demographic, and medical information [23]. Ages at diagnosis and family cancer history were obtained from the UPDB after sequencing and variant evaluation. Additional subjects were selected on the basis of being newly diagnosed pancreatic cancer cases ascertained at the $\mathrm{HCH}$ from July 2014 to April $2017(n=224)$. The pancreatic cancer cases ascertained during the interval July 2014-November 2015 $(n=151)$ were screened with a 59-gene custom research panel, and the cases ascertained during the interval December 2015-April $2017(n=73)$ were screened with a 14-gene custom clinical panel.

\section{Next-generation sequencing library preparation and custom targeted capture}

For research panel testing, blood-derived genomic DNA (100 ng) was sheared using a Covaris S2 instrument (Covaris, Woburn, MA, United States). Genomic libraries were prepared using the Ovation Ultralow Library System (NUGEN \# 0329) according to the manufacturer's instructions. Library enrichment for a 34 or 59-gene custom panel was done with the Roche SeqCap EZ Choice Library (cat\# 06266339001) and the SeqCap EZ Reagent Kit Plus v2 (NimbleGen \#06-953-247-001) using the manufacturer's protocol. Individual libraries were combined into pools of 6-12 prior to hybridization, and then super-pooled for up to 96 samples per sequencing lane. Captured libraries were sequenced on an Illumina HiSeq2000 channel using the HiSeq 101 Cycle Paired-End sequencing protocol.

On the strength of preliminary data from this study, $\mathrm{HCH}$ began systematically offering clinical panel predisposition testing beginning December 2015, without regard to family history. From December 2015 to April 2017 , clinical testing was offered to 73 sequential pancreatic cancer cases. Sixty-one pancreatic cancer patients accepted clinical testing with the 14-gene custom panel that was conducted by Invitae. The 12 individuals that declined were in poor health and/or did not see value in undergoing a genetic test. A complete list of genes captured is included in Additional file 1: Table S1.

Sequences from the Utah cohort with $\geq 100 \mathrm{X}$ mean coverage and 154 pancreatic cancer cases from the Cancer Genome Atlas (TCGA) [24] were analyzed using the USeq (useq.sourceforge.net) in-house pipeline, according to the Genome Analysis Toolkit (GATK v.3.3-0) best practices recommendations [25]. Variants with a mapping quality score less than 20 were excluded. ANNOVAR was used for variant functional annotation followed by conversion to Human Genome Variation Society (HGVS) nomenclature using Mutalyzer [26, 27].

\section{Sequence variant evaluation}

Truncating variants not present in the final exon of a gene were considered pathogenic. The following filters were used to exclude variants from further analysis: minor allele frequency $\geq 0.1 \%$ in one or more populations from the Exome Aggregation Consortium (ExAC) database; [28] synonymous/intronic variants with no predicted effect on splicing via MaxEntScan; [29] variants reported as probable-non-pathogenic/non-pathogenic by more than one source with no conflicting reports in ClinVar (www.ncbi.nlm.nih.gov/clinvar).

Variants of uncertain significance (VUS) were included if in silico predictions were suggestive of being relatively high probabilities of pathogenicity VUS (HiP-VUS). HiP-VUS had estimated prior probabilities of pathogenicity $>0.8$ based on calibrated in silico predictions from publicly available databases for the mismatch repair (MMR) genes (hci-lovd.hci.utah.edu), or BRCA1/2 (http://priors.hci.utah.edu/PRIORS/). HiP-VUS of this type were weighted according to their sequence analysis-based prior probability of pathogenicity (Prior_P) score. The VUS from the remaining genes were denoted HiP-VUS and included if at least three of the four missense analysis programs Align-GVGD, MAPP, Polyphen-2, and CADD predicted a severe score [30-34]. This filter corresponds with an $\mathrm{OR}=3.27$ when 
comparing early-onset breast cancer cases with matched controls [33]. Based on the likelihood ratios identified for $B R C A 1 / 2$, [35] this grouping was assigned a weight of 0.81. Canonical splice acceptor/donor variants predicted to impact splicing were given the weight of 0.97 if the effect of the variant had not been demonstrated experimentally [36]. Pathogenic variants and HiP-VUS detected by the 34-/59-gene panels were confirmed via Sanger sequencing. VUS reported by the Mayo Clinic [37] plus the non-TCGA ExAC (excluding the Finnish and undescribed populations), were graded with the same weights and severity to generate a bioinformatically equivalent set of HiP-VUS. An overview of the datasets and methods used for evaluation is shown (Fig. 1).

\section{Statistical analysis}

STATA V.13.1 (StataCorp, College Station, Texas, USA) was used to conduct meta-analyses, and calculate carrier percentages and 95\% confidence intervals. The meta-analyses to compare the carrier frequencies between different pancreatic cancer cohorts were conducted using Metaprop under a random effects model, and Freeman-Tukey transformation to stabilize the variances over the studies [38]. The weighted proportions of variant carriers in the unselected pancreatic cancer cases were compared to the corresponding proportions in the non-TCGA ExAC population to estimate Standardized Incidence Ratios (SIR) [39]. Tests of significance and confidence intervals were estimated based on a Poisson distribution [40]. For the meta-analysis and SIR calculation, the genes were split into subgroups of high- and moderate-risk cancer susceptibility genes. High- and moderate-risk were defined as genes with a cumulative risk at age $80>32 \%$ or between 19 and $32 \%$, respectively, for the cancer with which they are most closely associated [2]. The $\mathrm{R}$ package ggplot2 was used to plot the meta-analyses and SIRs [41].

\section{Results}

Identification of pathogenic variants and HiP-VUS in pancreatic cancer patients, unselected for family history

In an initial set of 66 pancreatic cancer cases unselected for family history of cancer, 4 pathogenic variants were identified in BRCA2, MSH6, PALB2, and STK11. After filtering VUS, 2 HiP-VUS in ATM remained (Table 1). After weighting, $8.5 \%$ of these pancreatic cancer cases carried a variant with potential medical management impact for relatives.

Two series of cases were used for internal replication. From a set of 147 pancreatic cancer cases undergoing an in-house custom 59-gene panel, 6 pathogenic variants were identified in ATM, BRCA1, BRCA2, MRE11A, and PALB2, and 6 HiP-VUS in ATM, BRCA2, CHEK2, MSH6, and TP53. In addition to in silico predictions, CHEK2 p.(T476 M) was found to be damaging in a functional assay for CHEK2 variants, and was thus weighted more strongly towards being pathogenic [42]. Subsequently, an additional set of pancreatic cancer

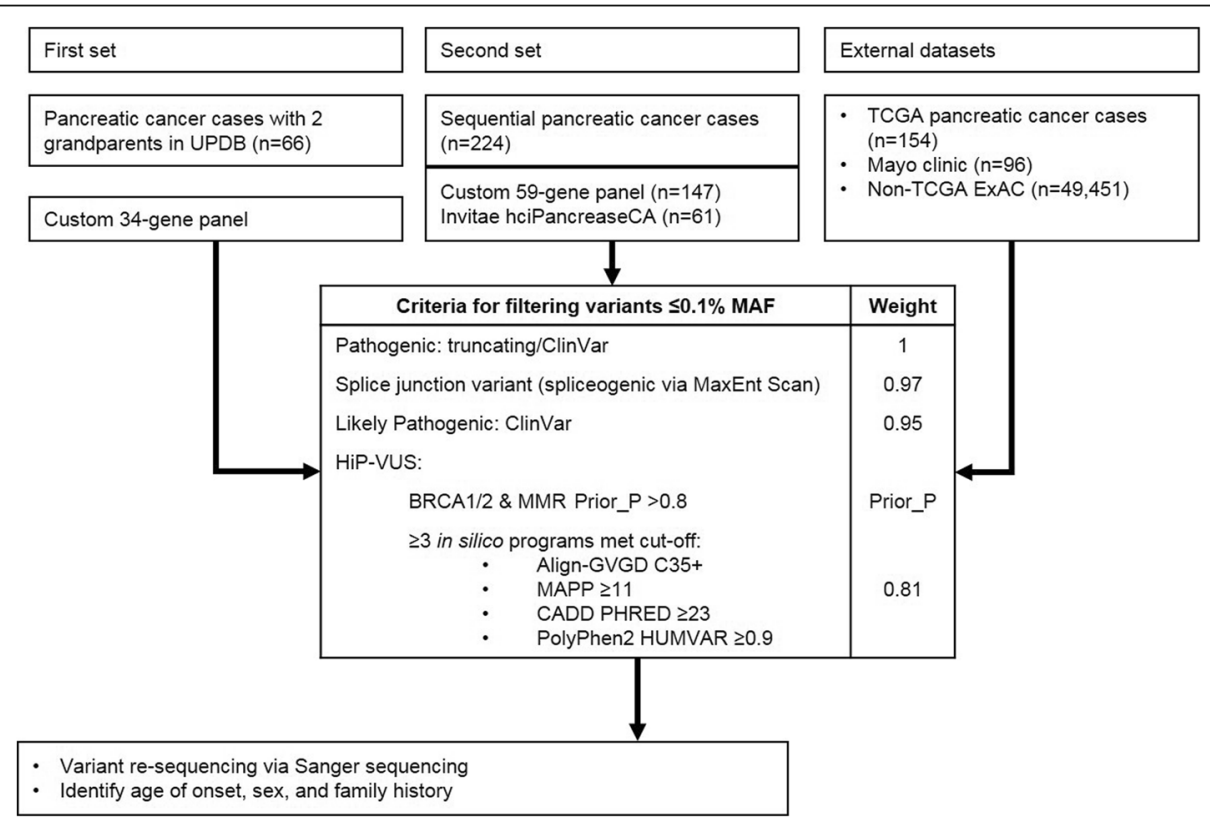

Fig. 1 Flow chart of methods. Includes the weighting assigned to filtered sequence variants. In the second set of unselected pancreatic cancer cases 16 cases failed testing with the custom 59-gene panel and/or declined testing with the Invitae hciPancreasCA panel. MAF = minor allele frequency; HiP-VUS = high probability of pathogenicity variant of uncertain significance; MMR - mismatch repair; Prior_P = sequence analysis-based prior probability of pathogenicity 
Table 1 Pathogenic variants and high probability of pathogenicity variants of uncertain significance (HiP-VUS) identified from a custom 34- or 59-gene panel and a clinical 14-gene panel in pancreatic cancer cases, unselected for family history

\begin{tabular}{|c|c|c|c|}
\hline Gene & HGVS Notation & Sex: Age of Onset & Carrier Weight \\
\hline \multicolumn{4}{|c|}{ Custom 34-gene panel $(n=66)$} \\
\hline ATM & c.7327C > G p.(R2443G) & M: $60 \mathrm{~s}$ & 0.81 \\
\hline ATM & c.8734A > G p.(R2912G) & $\mathrm{F}: 60 \mathrm{~s}$ & 0.81 \\
\hline BRCA2 & c.3873del p.(Q1291Hfs*2) & M: 50s & 1 \\
\hline MSH6 & c.3261dup p.(F1088Lfs*5) & F: $50 \mathrm{~s}$ & 1 \\
\hline PALB2 & c. 1240 C > T p. $($ R414*) & $\mathrm{F}: 60 \mathrm{~s}$ & 1 \\
\hline \multirow[t]{2}{*}{ STK11 } & c.738C > A p. $\left(Y 246^{*}\right)$ & M: 40s & 1 \\
\hline & \multicolumn{2}{|c|}{ Carrier Frequency: 5.62/66 = 8.52\% (3.87-17.7\%) } & \\
\hline \multicolumn{4}{|c|}{ Custom 59-gene panel $(n=147)$} \\
\hline ATM & c.1564_1565del p.(E522lfs*43) & M: $50 \mathrm{~s}$ & 1 \\
\hline ATM & c.8734A > G p.(R2912G) & M: 70s & 0.81 \\
\hline BRCA1 & c.68_69del p.(E23Vfs*17) & M: 70s & 1 \\
\hline BRCA2 & c.3974_3975insTGCT p.(T1325Cfs*4) & M: 70s & 1 \\
\hline BRCA2 & c.8447G > A p.(G2816D) & $\mathrm{F}: 60 \mathrm{~s}$ & 0.81 \\
\hline CHEK2 & c.1159A > G p.(T387A) & M: $80 \mathrm{~s}$ & 0.81 \\
\hline CHEK2 & c.1427C > T p.(T476 M) & F: $50 \mathrm{~s}$ & $0.99^{\mathrm{a}}$ \\
\hline MRE11A & c.923dupT p.(M309Hfs*8) & M: $50 \mathrm{~s}$ & 1 \\
\hline MRE11A & c.1516G > T p. $\left(\mathrm{E} 506^{*}\right)$ & $\mathrm{F}: 60 \mathrm{~s}$ & 1 \\
\hline MSH6 & c.3851C > T p.(T1284 M) & $\mathrm{F}: 60 \mathrm{~s}$ & 0.94 \\
\hline PALB2 & c.2167_2168del p.(M723Vfs*21) & M: $60 s^{c}$ & 1 \\
\hline RAD50 & c.3641G > A p.(R1214H) & F: $50 \mathrm{~s}$ & $-{ }^{a}$ \\
\hline TP53 & c.847C > T p.(R283C) & M: 60s & 0.81 \\
\hline \multicolumn{4}{|c|}{ Clinical 14-gene panel $(n=61)$} \\
\hline ATM & c.1402_1406delAAGAG p.(K468Vfs*17) & $\mathrm{F}: 40 \mathrm{~s}$ & 1 \\
\hline ATM & c. $2426 \mathrm{C}>$ A p. $\left(\mathrm{S} 809^{*}\right)$ & $\mathrm{F}: 80 \mathrm{~s}^{\mathrm{d}}$ & 1 \\
\hline ATM & c.3993 + 1G > A (splice donor) & $\mathrm{M}: 70 \mathrm{~s}^{\mathrm{e}}$ & $-\mathrm{b}$ \\
\hline BRCA2 & c.6275_6276delTT p.(L2092Pfs*7) & M:70s & $1^{\mathrm{b}}$ \\
\hline CDKN2A & c.301G > T p.(G101 W) & $F: 60 s^{f}$ & 1 \\
\hline CHEK2 & c.349A > G p.(R117G) & F:70s & 0.95 \\
\hline MSH6 & c.1444C > T p.(R482*) & $F: 70 s^{9}$ & 1 \\
\hline \multirow[t]{2}{*}{ TP53 } & c.1015G > A p.(E339K) & F:70s & 0.81 \\
\hline & \multicolumn{3}{|c|}{ Carrier Frequency: $17.89 / 208=8.60 \%$ (5.50-13.20\%) } \\
\hline
\end{tabular}

HGVS Human Genome Variation Society

a,b The same individual carried both variants, so carrier weight was combined and only counted once. Additional cancers: ${ }^{\mathrm{c}} \mathrm{CRC}$ in $40 \mathrm{~s}$; ${ }^{\mathrm{d}}$ lung in $80 \mathrm{~s}$ and $\mathrm{CRC}$ in $60 \mathrm{~s}$; eprostate (Gleason 7) in $70 \mathrm{~s} ;{ }^{f}$ melanoma in $40 \mathrm{~s}$ and cervical in $30 \mathrm{~s} ;{ }^{9}$ breast in $50 \mathrm{~s}$, endometrial in $50 \mathrm{~s}$, and urethral in $70 \mathrm{~s}$

cases $(n=61)$ were tested with the 14-gene clinical panel, which identified 6 pathogenic variants and 2 HiP-VUS in 7 patients (Table 1). All pathogenic variants and HiP-VUS were identified in genes included in the original 34-gene panel. After weighting carriers, $8.6 \%$ of the pancreatic cancer cases from the latter two sets, unselected for family history, carried a variant with potential medical impact. A full list of rare variants with corresponding in silico information is available in Additional file 1: Table S2.
Post-variant evaluation of genetic testing eligibility

In order to estimate the proportion of pancreatic cancer cases with pathogenic variants or HiP-VUS that would have qualified for genetic testing, the family histories were compared to NCCN guidelines [43]. Pedigree data regarding familial cancer were available from UPDB for the carriers of pathogenic variants and HiP-VUS in 6 of the initial set of 66 pancreatic cancer patients (Additional file 2: Figure S1). Self-reported family history information was also available for the final set of 61 
patients that underwent the Invitae clinical panel, including the 7 carriers of pathogenic variants or HiP-VUS. Among the 13 identified carriers, the STK11 carrier had a clinical diagnosis of Peutz-Jegher syndrome with multiple affected relatives, and 9 additional patients met criteria for $\mathrm{HBOC}$ or Lynch syndrome genetic testing. Thus, more than $23 \%$ of these carriers would not have qualified for testing under current guidelines.

Once a pathogenic variant is identified, cascade testing for that variant can occur on biological relatives to identify individuals who would benefit from $\mathrm{HBOC}$ or CRC preventive measures. For three of the five pancreatic cancer cases with positive results with the clinical panel, 17 biological relatives have undergone cascade genetic testing thus far, 10 of whom have tested positive for the family pathogenic variant. Of note, 21 (29\%) pancreatic cancer cases who underwent the clinical panel passed away since the beginning of the study, 17 of whom had undergone testing. This suggests that having a family member(s) present during pre-test counseling and delegated to receive results may be beneficial in the context of utilization of pancreatic cancer as a sentinel for HBOC or Lynch syndrome.

\section{Meta-analysis of carrier proportions across studies}

The $\mathrm{HCH}$ sets of pancreatic cancer cases were combined with a published study of unselected pancreatic cancer cases from the Mayo Clinic $(n=96)$, [37] plus the pancreatic cancer cases from TCGA $(n=154)$, in a meta-analysis (Fig. 2; Additional file 1: Table S3; Additional file 3: Table S4). Among unselected pancreatic cancer cases, 3.9\% $\left(p=2.1 \times 10^{-13}\right)$ carried a clearly pathogenic variant in a high-risk cancer susceptibility gene which includes pancreatic cancer in its tumor spectrum [8]. Weighed inclusion of HiP-VUS increased the proportion to $5.1 \%\left(p=6.8 \times 10^{-18}\right)$. For the moderate-risk homologous recombination repair (HRR) breast cancer genes ATM, BARD1, CHEK2, and NBN, $[2,44] 3.3 \%\left(p=7.2 \times 10^{-04}\right)$ of unselected pancreatic cancer cases carried a clearly pathogenic variant, and weighted inclusion of HiP-VUS increased the proportion to $5.1 \%\left(p=2.3 \times 10^{-08}\right)$. Including all the high-risk genes and the moderate-risk HRR breast cancer genes, $7.9 \%\left(p=1.4 \times 10^{-12}\right)$ of unselected pancreatic cancer cases carry a clearly pathogenic variant, and $10.4 \%\left(p=9.1 \times 10^{-17}\right)$ carry either a clearly pathogenic variant or weighted HiP-VUS with elevated probability of pathogenicity that could enable the at-risk relatives to qualify for preventive $\mathrm{HBOC}$ or CRC measures.

Further, the gene burdens observed in the Utah, Mayo, and TCGA were compared to the non-TCGA ExAC $(n=49,451$, excluding the Finnish and other subpopulations) as a population sample to determine SIR for subgroups of genes (Fig. 3, Additional file 3: Table S5). As a group, the high-risk susceptibility genes had a SIR $=2.6\left(p=1.6 \times 10^{-05}\right)$. The moderate-risk HRR genes had a slightly lower SIR $=2.3\left(p=2.0 \times 10^{-05}\right)$.

\section{Discussion}

From the 16 pathogenic and $11 \mathrm{HiP}-\mathrm{VUS}$ carriers identified through systematic panel testing of pancreatic

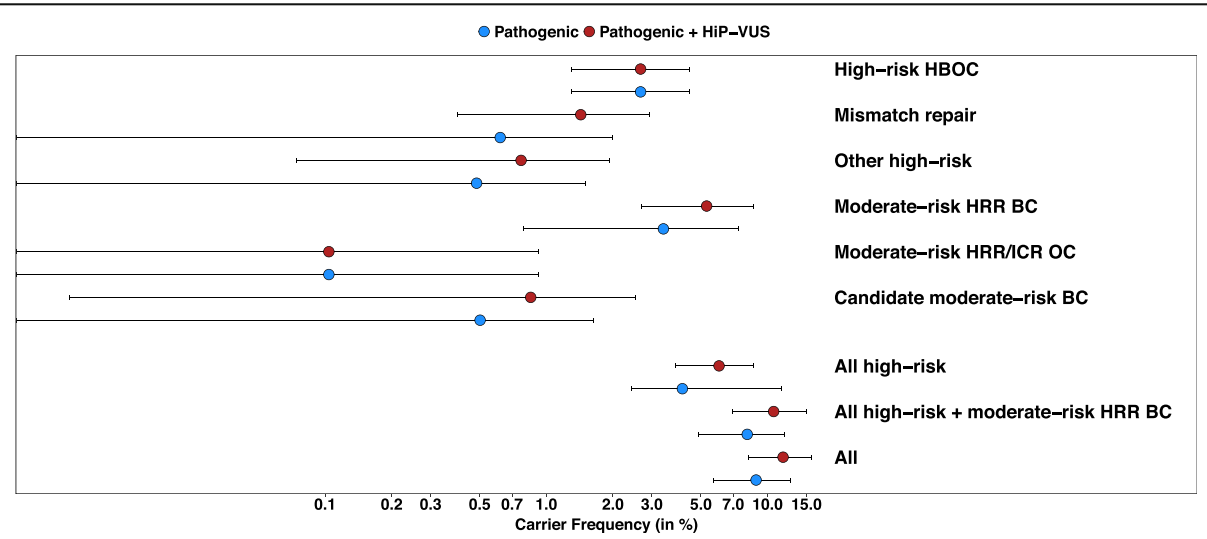

Fig. 2 Proportion of carriers of pathogenic variants and high probability of pathogenicity variants of uncertain significance (HiP-VUS) in unselected pancreatic cancer. Results based on a meta-analysis of the unselected pancreatic cancer cases from the Huntsman Cancer Hospital $(\mathrm{HCH})$, the Mayo Clinic, and the pancreatic cancer cases from The Cancer Genome Atlas (TCGA). Carrier frequency point estimates and 95\% confidence intervals for groups of genes are presented on a log-scale. A list of genes contained within each analysis group is provided in Additional file 1: Table S1. The breakdown of results by study is described in Additional file 1: Table S3. HBOC = Hereditary Breast and Ovarian Cancer; HRR = Homologous Recombination and Repair; ICR = Interstrand Crosslink Repair; OC = Ovarian Cancer; BC = Breast Cancer 


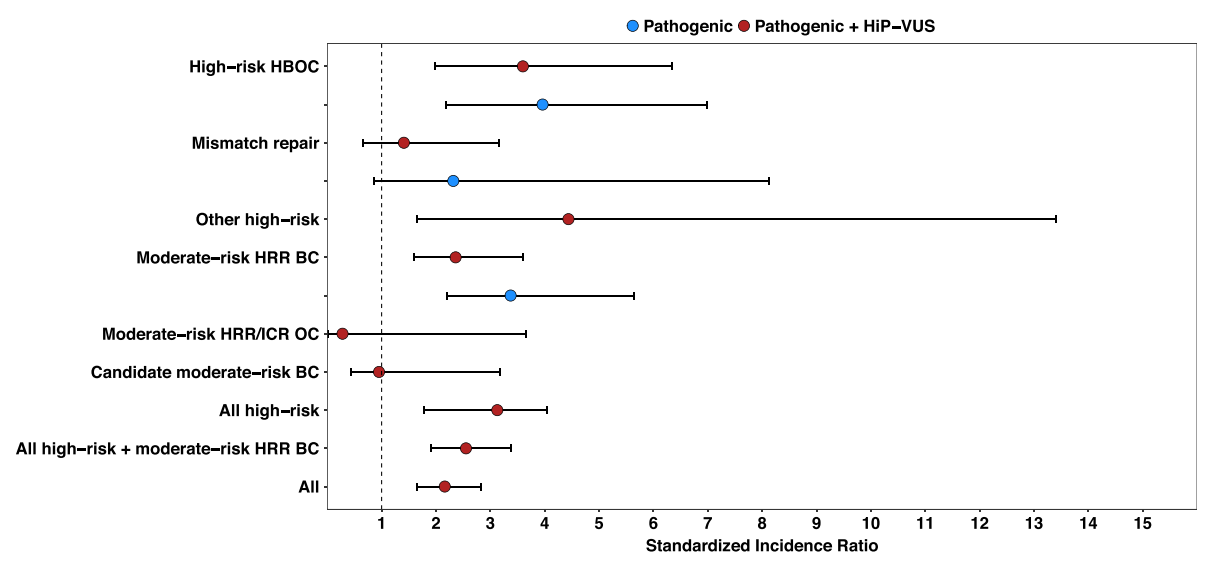

Fig. 3 Standardized incidence ratios for cancer susceptibility gene groups in unselected pancreatic cancer cases. The carrier frequencies from the meta-analysis of the cases and the Exome Aggregation Consortium excluding the Cancer Genome Atlas (non-TCGA ExAC) are detailed in Additional file 3: Table S5. A list of genes contained within each analysis group is provided in Additional file 1: Table S1. Error bars represent 95\% confidence intervals. $\mathrm{HBOC}=$ Hereditary Breast and Ovarian Cancer; HRR = Homologous Recombination and Repair; ICR =Interstrand Crosslink Repair; OC = Ovarian Cancer; BC = Breast Cancer

cancer cases unselected for family history, we estimate that $2.7 \%(95 \%$ CI: $1.4-4.4)$ carry a pathogenic allele of a high-risk HBOC gene (BRCA1, BRCA2, or PALB2) and $1.3 \%$ (95\% CI: $0.3-2.8$ ) of probands carry a pathogenic allele of a Lynch Syndrome (LS)-associated MMR gene (MLH1, MSH2, PMS2, or MSH6). Adding other high-risk genes such as TP53, CDKN2A, and STK11 results in 5.1\% (95\% CI: 3.3-7.2) of pancreatic cancer cases with a sequence variant that would alter medical management of healthy at-risk relatives: i.e. MRI in addition to mammography or early colonoscopy (Fig. 2) [7, 9, 45-47]. An additional 5.1\% (95\% CI: 2.4-8.5) are estimated to carry a pathogenic allele of a moderate-risk breast cancer susceptibility gene (i.e., ATM, BARD1, CHEK2, or $N B N$ ) bringing the total proportion of estimated carriers to $10.4 \%$ (95\% CI: 6.5-14.9). Here we note that ATM and CHEK2 have recently been added to NCCN's list of genes with associated medical action for breast cancer [7]. Focusing on individual genes, the top four genes with potential medical impact for at-risk relatives, based on weighted counts, were $A T M$ (identified in 7 cases), BRCA2 (4 cases), CHEK2 (3 cases), and MSH6 (3 cases).

The precedent for testing all pancreatic cancer patients comes from what has been accepted and learned from universal testing of all CRCs for LS. Universal LS testing, with immunohistochemical (IHC) or microsatellite instability (MSI)-based pre-screen of tumors followed by germline testing for indicated individuals, is recommended for newly diagnosed CRC cases [45, 48]. This strategy may soon be overtaken by germline DNA panel testing for LS due to 1) rapid decline of panel testing cost, 2) superiority of specificity and sensitivity, and 3) evidence that pre-screening delays genetic testing, which results in a subsequent $\sim 50 \%$ loss in follow up by patients [49-56]. Indeed, a health economics analysis recently published by Erten et al. [56] concluded that universal testing of CRC patients for LS based on sequencing alone will become more cost effective than the two-step test when the cost of MMR gene sequencing drops to or below $\$ 609$ USD, echoing a similar finding by Gould-Suarez et al. [56, 57]. Based on our results, universal testing of pancreatic cancer patients using a panel test would identify pathogenic variants or HiP-VUS in MMR genes at a frequency similar to what is detected with universal screening of CRC patients, 1.3 and $1.2 \%$ respectively [56].

In a recent study, $11.8 \%$ of unselected patients with metastatic prostate cancer were found to carry pathogenic variants in DNA-repair genes [58]. Pritchard et al. suggest that this proportion of metastatic prostate cancer cases is high enough to utilize metastatic prostate cancer as a sentinel for cancer predisposition testing. The $11.8 \%$ proportion observed in metastatic prostate cancer is similar to the $10.4 \%$ observed in this meta-analysis of pancreatic cancer cases. For these patients, universal panel testing offers critical time and convenience advantages over step-wise testing strategies, resulting in decreased loss to follow up or mortality and correspondingly increased benefit to at-risk relatives.

Lastly, there are an increasing number of options for targeted treatments based on germline mutations. PARP inhibitors show promise in pancreatic cancer, include olaparib and rucaparib (which are FDA approved in ovarian cancer), as well as veliparib (or ABT-888) which is in 
clinical trials [59]. Most patients with pathogenic germline $B R C A 1, B R C A 2$, or PALB2 variants would be expected to respond. Solid tumors with MMR deficiency often respond to immunotherapy [60]. The US Food and Drug Administration (FDA) has granted accelerated approval to pembrolizumab (Keytruda) for pediatric and adult patients with microsatellite unstable cancers, a hallmark molecular feature of Lynch syndrome related cancers [59]. The availability of targeted treatments increases the utility of testing for pancreatic cancer patients themselves, in addition to the prevention and screening benefits for relatives.

\section{Conclusions}

Our study adds to the increasing body of evidence that pancreatic cancer is an indicator of hereditary cancer predisposition. Identifying cases who carry mutations in genes associated with clinical recommendations will allow relatives to benefit from screening and prevention strategies for the range of cancer risks conferred. Increasingly, the finding of a germline mutation in pancreatic cancer patients may also impact their treatment. The benefits of genetic testing of all pancreatic cancer cases mirrors other cancers for which routine evaluation has become standard of care. Significant morbidity and poor prognosis may make this a uniquely challenging population to offer genetic counseling and testing. Research on the inherited basis of pancreatic cancer should be paired with psychosocial and behavioral studies to determine how best to incorporate genetic testing into the care of these patients and to ensure that findings are optimally used to benefit families.

\section{Additional files}

Additional file 1: Table S1. contains the list of the genes used in the study, as well as indicators for which pathway they belong to in subsequent analyses. Table S2. is the list of rare variants with corresponding in silico scores. Table S3. contains the total counts that were used to create Fig. 2. (XLSX 73 kb)

Additional file 2: Figure S1. The pancreatic cancer cases with Utah Population Database (UPDB) genealogies with cancer information. (JPG 847 kb)

Additional file 3: Table S4. Is a list of reports/genes used for metaanalysis. Table S5. is the values that were used to create Fig. 3. (DOCX 34 kb)

\section{Abbreviations}

CRC: colorectal cancer; ExAC: Exome Aggregation Consortium; FDA: US Food and Drug Administration; GATK: Genome Analysis Toolkit; HBOC: hereditary breast and ovarian cancer; HCH: Huntsman Cancer Hospital; HGVS: Human Genome Variation Society; HiP-VUS: high probabilities of pathogenicity variants of uncertain significance; IHC: immunohistochemical; LS: Lynch Syndrome; MMR: mismatch repair; MSI: microsatellite instability; SIR: Standardized Incidence Ratios; TCGA: the Cancer Genome Atlas; UPDB: Utah Population Database; VUS: Variants of uncertain significance

\section{Acknowledgements}

We acknowledge and appreciate the families for their continued support and participation in our studies. We would like to thank Angela K. Snow and
Nykole R. Sutherland for contributions of sequencing. We would also like to thank Ken R. Smith and the Utah Population Database team for enabling this project. The results published here are in part based upon data generated by The Cancer Genome Atlas managed by the NCI and NHGRI. Information about TCGA can be found at http://cancergenome.nih.gov. The authors would also like to thank the Exome Aggregation Consortium and the groups that provided exome variant data for comparison. A full list of contributing groups can be found at http://exac.broadinstitute.org/about

\section{Funding}

This research was supported by United States National Institutes of Health (NIH) National Cancer Institute (NCl) grant R01CA164138; NCl grant P30CA042014 (support of Genetic Counseling Shared Resource), by the Utah Genome Project; by the Canadian Institutes of Health Research (CIHR) for the CIHR Team in Familial Risks of Breast Cancer program; by the Government of Canada through Genome Canada and the Canadian Institutes of Health Research, and the Ministère de l'enseignement supérieur, de la recherche, de la science, et de la technologie du Québec through Génome Québec; by $\mathrm{NIH} \mathrm{NCl} \mathrm{Cancer} \mathrm{Center} \mathrm{Support} \mathrm{Grant} \mathrm{P30CA042014;} \mathrm{and} \mathrm{by} \mathrm{the} \mathrm{Huntsman}$ Cancer Foundation.

BAT is a National Health and Medical Research Council CJ Martin Early Career Fellow. ELY was supported by the National Institutes of Health under Ruth L. Kirschstein National Research Service Award T32HG008962 from the National Human Genome Research Institute. The content is solely the responsibility of the authors and does not necessarily represent the official views of the National Institutes of Health.

\section{Availability of data and materials}

List of complete list of identified variants from in-house custom panel available upon request from Sean V. Tavtigian.

\section{Authors' contributions}

ELY and SVT were involved in all aspects of manuscript. BAT was involved in DNA sequencing, analysis and interpretation of data, the meta-analysis and additional statistical analysis. DWN made substantial contributions to the study concept and design, and acquisition of data. MAF, TW, RB, LN, DEG, SJM, LACA were involved in analysis and interpretation of data as well as significant contributions of intellectual content. AG, CK, WKK are genetic counselors at the Familial Cancer Assessment Clinic at the Huntsman Cancer Hospital, and were involved in the acquisition of pancreatic cancer patients for both the research and clinical multigene panel. Additionally, they identified pancreatic cancer patients that met NCCN eligibility for genetic testing and drafted and edited substantial portions of manuscript creation pertaining to NCCN guidelines. JB and AF were crucial in identifying pancreatic cancer patients in UPDB with the correct requirements as well as generating pedigrees for those pancreatic cancer cases that carried a P/LP variant or HiP-VUS. All authors have read and approved the final manuscript.

\section{Ethics approval and consent to participate}

This study was approved by the Institutional Review Board of the University of Utah. All participants gave written consent, which included DNA sampling for molecular studies and access to medical records.

\section{Competing interests}

The authors declare that they have no competing interests.

\section{Publisher's Note}

Springer Nature remains neutral with regard to jurisdictional claims in published maps and institutional affiliations.

\section{Author details}

${ }^{1}$ Department of Oncological Sciences, University of Utah School of Medicine, Salt Lake City, United States. ${ }^{2}$ Huntsman Cancer Institute, University of Utah School of Medicine, Salt Lake City, United States. ${ }^{3}$ Centre for Epidemiology and Biostatistics, School of Population and Global Health, University of Melbourne, Melbourne, Australia. ${ }^{4}$ Division of Genetic Epidemiology, Department of Internal Medicine, University of Utah, Salt Lake City, United States. ${ }^{5}$ Department of Surgery, University of Utah School of Medicine, Salt Lake City, United States. 'Division of Oncology, Department of Medicine, University of Utah, Salt Lake City, United States. ${ }^{7}$ Population Sciences, Huntsman Cancer Institute, University of Utah, Salt Lake City, United States. 
${ }^{8}$ Department of Surgery and Arizona Cancer Center, University of Arizona, Tucson, United States. ${ }^{9}$ Department of Dermatology, University of Utah School of Medicine, Salt Lake City, United States. ${ }^{10}$ George E. Wahlen Department of Veterans Affairs Medical Center, Salt Lake City, United States.

\section{Received: 26 December 2017 Accepted: 1 June 2018} Published online: 27 June 2018

\section{References}

1. Walsh T, Lee MK, Casadei S, Thornton AM, Stray SM, Pennil C, et al. Detection of inherited mutations for breast and ovarian cancer using genomic capture and massively parallel sequencing. Proc. Natl. Acad. Sci. U. S. A. $2010 ; 107: 12629-12633$. Available from: http://www.pubmedcentral.nih. gov/articlerender.fcgi?artid=2906584\&tool=pmcentrez\&rendertype=abstract. [cited 2010 Dec 8]

2. Easton DF, Pharoah PDP, Antonious AC, Tischkowitz M, Tavtigian SV, Nathanson KL, et al. Gene-panel sequencing and the prediction of breastCancer risk. N Engl J Med. 2015;372:2243-57.

3. Hall MJ, Forman AD, Pilarski R, Wiesner G, Giri VN. Gene panel testing for inherited cancer risk. J Natl Compr Cancer Netw. 2014;12:1339-46. Available from: http://www.ncbi.n/m.nih.gov/pubmed/25190699

4. Salo-Mullen EE, O'Reilly EM, Kelsen DP, Ashraf AM, Lowery MA, Yu KH, et al. Identification of germline genetic mutations in patients with pancreatic cancer. Cancer. 2015;121:4382-8. Available from: http://doi.wiley.com/10. 1002/cncr.29664

5. Harinck F, Poley JW, Kluijt I, Fockens P, Bruno MJ, Dutch Research Group of Pancreatic Cancer Surveillance in High-Risk Individuals. Is early diagnosis of pancreatic cancer fiction? Surveillance of individuals at high risk for pancreatic cancer. Dig. Dis. 2010;28:670-8. Available from: http://www.ncbi. nlm.nih.gov/pubmed/21088419

6. Chari ST, Kelly K, Hollingsworth MA, Thayer SP, Ahlquist DA, Andersen DK, et al. Early detection of sporadic pancreatic cancer: summative review. Pancreas. 2015;44:693-712. Available from: http://www.pubmedcentral.nih. gov/articlerender.fcgi?artid=4467589\&tool=pmcentrez\&rendertype=abstract

7. Daly MB, Pilarski R, Axilbund JE, Berry M, Buys SS, Crawford B, et al. Genetic/ familial high-risk assessment: breast and ovarian, version 2.2015. J Natl Compr Cancer Netw. 2016;14:153-62. Available from: http://www.ncbi.nlm nih.gov/pubmed/26850485

8. Whitcomb DC, Shelton CA, Brand RE. Genetics and genetic testing in pancreatic cancer. Gastroenterology. 2015;149:1-13. Available from: http:// linkinghub.elsevier.com/retrieve/pii/S0016508515010896

9. Leachman SA, Carucci J, Kohlmann W, Banks KC, Asgari MM, Bergman W, et al. Selection criteria for genetic assessment of patients with familial melanoma. J Am Acad Dermatol. 2009;61:1-14.

10. Kastrinos F, Mukherjee B, Tayob N, Wang F, Sparr J, Raymond VM, et al. Risk of pancreatic cancer in families with lynch syndrome. JAMA. 2009;302:17905. Available from: http://www.ncbi.nlm.nih.gov/pubmed/29151953

11. Bujanda L, Herreros-Villanueva M. Pancreatic Cancer in lynch syndrome patients. J Cancer. 2017:8:3667-74. Available from: http://www.ncbi.nlm.nih. gov/pubmed/29151953

12. Mandelker D, Zhang L, Kemel Y, Stadler ZK, Joseph V, Zehir A, et al. Mutation Detection in Patients With Advanced Cancer by Universal Sequencing of Cancer-Related Genes in Tumor and Normal DNA vs Guideline-Based Germline Testing. JAMA. 2017:318:825. Available from: http://jama.jamanetwork.com/article.aspx?doi=10.1001/jama.2017.11137

13. Shindo K, Yu J, Suenaga M, Fesharakizadeh S, Cho C, Macgregor-Das A, et al. Deleterious germline mutations in patients with apparently sporadic pancreatic adenocarcinoma. J Clin Oncol. 2017;JCO2017723502 Available from: http://www.ncbi.n/m.nih.gov/pubmed/28767289

14. Catts ZA-K, Baig MK, Milewski B, Keywan C, Guarino M, Petrelli N. Statewide Retrospective Review of Familial Pancreatic Cancer in Delaware, and Frequency of Genetic Mutations in Pancreatic Cancer Kindreds. Ann. Surg. Oncol. 2016;99. Available from: http://link.springer.com/10.1245/s10434-015-5026-x

15. Kim DH, Crawford B, Ziegler J, Beattie MS. Prevalence and characteristics of pancreatic cancer in families with BRCA1 and BRCA2 mutations. Fam. Cancer. 2009:8:153-8. Available from: http://www.ncbi. nlm.nih.gov/pubmed/18855126

16. Grant RC, Selander I, Connor AA, Selvarajah S, Borgida A, Briollais L, et al. Prevalence of germline mutations in Cancer predisposition genes in patients with pancreatic Cancer. Gastroenterology. 2015;148:556-64. [cited
2015 Jan 22]; Available from: http://www.ncbi.nlm.nih.gov/pubmed/ 25479140

17. Holter S, Borgida A, Dodd A, Grant R, Semotiuk K, Hedley D, et al. Germline BRCA mutations in a large clinic-based cohort of patients with pancreatic adenocarcinoma. J Clin Oncol. 2015;33:3124-9.

18. Hahn SA, Greenhalf B, Ellis I, Sina-Frey M, Rieder H, Korte B, et al. BRCA2 germline mutations in familial pancreatic carcinoma. J Natl Cancer Inst. 2003;95:214-21. Available from: http://www.ncbi.nlm.nih.gov/pubmed/ 12569143

19. Easton DF, Matthews FE, Ford D, Swerdlow AJ, Peto J. Cancer mortality in relatives of women with ovarian cancer: the OPCS study. Office of Population Censuses and Surveys. Int J Cancer. 1996;65:284-94. Available from: http://www.ncbi.nlm.nih.gov/pubmed/8575846

20. Lal G, Liu G, Schmocker B, Kaurah P, Ozcelik H, Narod SA, et al. Inherited predisposition to pancreatic adenocarcinoma: role of family history and germ-line p16, BRCA1, and BRCA2 mutations. Cancer Res. 2000;60:409-16. Available from: http://www.ncbi.n/m.nih.gov/pubmed/10667595

21. Humphris JL, Johns AL, Simpson SH, Cowley MJ, Pajic M, Chang DK, et al. Clinical and pathologic features of familial pancreatic cancer. Cancer. 2014; 120:1-7. [cited 2014 Oct 25]; Available from: http://www.ncbi.nlm.nih.gov/ pubmed/25313458

22. Lucas AL, Frado LE, Hwang C, Kumar S, Khanna LG, Levinson EJ, et al. BRCA1 and BRCA2 germline mutations are frequently demonstrated in both highrisk pancreatic cancer screening and pancreatic cancer cohorts. Cancer. 2014;120:1-8. [cited 2014 May 7]; Available from: http://www.ncbi.nlm.nih. gov/pubmed/24737347

23. Skolnick M. The Utah genealogical database: a resource for genetic epidemiology. Banbury Rep. 1980;4:285-97.

24. Tomczak K, Czerwińska P, Wiznerowicz M. The Cancer genome atlas (TCGA): an immeasurable source of knowledge. Wspolczesna Onkol. 2015;1A:A68-77.

25. DePristo MA, Banks E, Poplin R, Garimella KV, Maguire JR, Hartl C, et al. A framework for variation discovery and genotyping using next-generation DNA sequencing data. Nat. Genet. 2011:43:491-8. Available from: http://dx. doi.org/10.1038/ng.806

26. Wildeman M, van Ophuizen E, den Dunnen JT, Taschner PEM. Improving sequence variant descriptions in mutation databases and literature using the Mutalyzer sequence variation nomenclature checker. Hum Mutat. 2008; 29:6-13. Available from: http://www.ncbi.n/m.nih.gov/pubmed/16835861

27. Wang K, Li M, Hakonarson H. ANNOVAR: functional annotation of genetic variants from high-throughput sequencing data. Nucleic Acids Res. 2010;38: e164. Available from: http://www.ncbi.n/m.nih.gov/pubmed/20601685

28. Lek M, Karczewski KJ, Minikel EV, Samocha KE, Banks E, Fennell T, et al. Analysis of protein-coding genetic variation in 60,706 humans. Nature. 2016; 536:285-91. Available from: http://www.nature.com/doifinder/10.1038/ nature19057

29. Yeo G, Burge CB. Maximum entropy modeling of short sequence motifs with applications to RNA splicing signals. J Comput Biol. 2004;11:377-94. [cited 2013 Feb 13]; Available from: http://www.ncbi.nlm.nih.gov/pubmed/15285897

30. Tavtigian SV, Deffenbaugh a M, Yin L, Judkins T, Scholl T, Samollow PB, et al. Comprehensive statistical study of 452 BRCA1 missense substitutions with classification of eight recurrent substitutions as neutral. J Med Genet. 2006;43: 295-305. [cited 2013 Nov 7]; Available from: http://www.pubmedcentral.nih. gov/articlerender.fcgi?artid=2563222\&tool=pmcentrez\&rendertype=abstract

31. Adzhubei I, Jordan DM, Sunyaev SR. Predicting Functional Effect of Human Missense Mutations Using PolyPhen-2. Curr. Protoc. Hum. Genet. 2013; Chapter 7:-Unit7.20. [cited 2013 Feb 5]; Available from: http://www.ncbi. nlm.nih.gov/pubmed/23315928

32. Kircher M, Witten DM, Jain P, O'Roak BJ, Cooper GM, Shendure J. A general framework for estimating the relative pathogenicity of human genetic variants. Nat. Genet. 2014:46:310-5. [cited 2014 Mar 3]; Available from: http://www.nature.com/doifinder/10.1038/ng.2892

33. Young EL, Feng BJ, Stark AW, Damiola F, Durand G, Forey N, et al. Multigene testing of moderate-risk genes: be mindful of the missense. J Med Genet. 2016:53:366-76. Available from: http://jmg.bmj.com/lookup/doi/ 10.1136/jmedgenet-2015-103398\%5Cn http://www.ncbi.n/m.nih.gov/ pubmed/26787654

34. E a S, Sidow A. Physicochemical constraint violation by missense substitutions mediates impairment of protein function and disease severity. Genome Res. 2005;15:978-86. [cited 2013 Feb 5] Available from: http:// www.pubmedcentral.nih.gov/articlerender.fcgi?artid=1172042\&tool= pmcentrez\&rendertype=abstract 
35. Tavtigian SV, Byrnes GB, Goldgar DE, Thomas A. Classification of rare missense substitutions, using risk surfaces, with genetic- and molecularepidemiology applications. Hum Mutat. 2008;29:1342-54. Available from: http://www.ncbi.nlm.nih.gov/pubmed/18951461

36. Vallée MP, Di STL, Nix DA, Paquette AM, Parsons MT, Bell R, et al. Adding In Silico Assessment of Potential Splice Aberration to the Integrated Evaluation of BRCA Gene Unclassified Variants. Hum. Mutat. 2016; Available from: http://www.ncbi.nlm.nih.gov/pubmed/26913838

37. Hu C, Hart SN, Bamlet WR, Moore RM, Nandakumar K, Eckloff BW, et al. Prevalence of Pathogenic Mutations in Cancer Predisposition Genes among Pancreatic Cancer Patients. Cancer Epidemiol Biomark Prev. 2016;25:207-11. Available from: http://cebp.aacrjournals.org/cgi/doi/10.1158/1055-9965.EPI15-0455

38. Freeman MF, Tukey JW. Transformations related to the angular and the square root. Ann Math Stat. 1950;21:607-11.

39. Lek M, Karczewski K, Minikel E, Samocha K, Banks E, Fennell T, et al. Analysis of protein-coding genetic variation in 60,706 humans. bioRxiv. 2015:1-26. Available from: http://biorxiv.org/content/early/2015/10/30/030338.abstract

40. Rosner B. Fundamentals of biostatistics. 2nd ed. Boston: Duxbury Press; 1986

41. Wickham H. ggplot2: elegant graphics for data analysis. Springer-Verlag New York; 2009

42. Roeb W, Higgins J, King M. Response to DNA Damage of CHEK2 Missense Mutations in Familial Breast Cancer. Hum. Mol. Genet. 2012;21:2738-44. [cited 2012 Apr 9] Available from: http://www.ncbi.nlm.nih.gov/pubmed/22419737

43. Daly MB, Pilarski R, Berry M, Buys SS, Farmer M, Friedman S, et al. NCCN guidelines insights: genetic/familial high-risk assessment: breast and ovarian, version 2.2017. J Natl Compr Cancer Netw. 2017;15:9-20. Available from: http://www.jncen.org/content/15/1/9.long

44. Couch FJ, Shimelis H, Hu C, Hart SN, Polley EC, Na J, et al. Associations Between Cancer Predisposition Testing Panel Genes and Breast Cancer. JAMA Oncologia. 2017;3:1190-6. Available from: http://oncology. jamanetwork.com/article.aspx?doi=10.1001/jamaoncol.2017.0424

45. Provenzale D, Jasperson K, Ahnen DJ, Aslanian H, Bray T, Cannon JA, et al. Colorectal Cancer screening, version 1.2015. J Natl Compr Cancer Netw. 2015;13:959-68. quiz 968. Available from: http://www.jnccn.org/content/13/ 8/959.full.pdf

46. Villani A, Tabori U, Schiffman J, Shlien A, Beyene J, Druker H, et al. Biochemical and imaging surveillance in germline TP53 mutation carriers with Li-Fraumeni syndrome: a prospective observational study. Lancet. Oncol. 2011;12:559-67. Available from: http://www.ncbi.nlm.nih.gov/ pubmed/21601526

47. van der Post RS, Vogelaar IP, Carneiro F, Guilford P, Huntsman D, Hoogerbrugge $\mathrm{N}$, et al. Hereditary diffuse gastric cancer: updated clinical guidelines with an emphasis on germline $\mathrm{CDH} 1$ mutation carriers. J Med Genet. 2015;52:361-74. Available from: http://www.pubmedcentral.nih.gov/ articlerender.fcgi?artid=4453626\&tool=pmcentrez\&rendertype=abstract

48. Evaluation of Genomic Applications in Practice and Prevention (EGAPP) Working Group. Recommendations from the EGAPP Working Group: genetic testing strategies in newly diagnosed individuals with colorectal cancer aimed at reducing morbidity and mortality from Lynch syndrome in relatives. Genet. Med. 2009;11:35-41. Available from: http://www. pubmedcentral.nih.gov/articlerender.fcgi?artid=2743612\&tool= pmcentrez\&rendertype $=$ abstract

49. Hartman DJ, Brand RE, Hu H, Bahary N, Dudley B, Chiosea SI, et al. Lynch syndrome-associated colorectal carcinoma: Frequent involvement of the left colon and rectum and late-onset presentation supports a universal screening approach. Hum. Pathol. 2013;44:2518-28. Available from: http:// dx.doi.org/10.1016/j.humpath.2013.06.012

50. Heald B, Plesec T, Liu X, Pai R, Patil D, Moline J, et al. Implementation of universal microsatellite instability and immunohistochemistry screening for diagnosing lynch syndrome in a large academic medical center. J Clin Oncol. 2013:31:1336-40.

51. Kidambi TD, Blanco A, Myers M, Conrad P, Loranger K, Terdiman JP. Selective versus universal screening for lynch syndrome: a six-year clinical experience. Dig. Dis. Sci. 2014;60:2463-9. Available from: http://dx.doi.org/10. 1007/s10620-014-3234-z

52. Musulén E, Sanz C, Muñoz-Mármol AM, Ariza A. Mismatch repair protein immunohistochemistry: A useful population screening strategy for Lynch syndrome. Hum. Pathol. 2014;45:1388-96. Available from: http://dx.doi.org/ 10.1016/j.humpath.2014.02.012
53. Hampel $H$, Frankel WL, Martin E, Arnold M, Khanduja K, Kuebler P, et al. Feasibility of screening for lynch syndrome among patients with colorectal cancer. J Clin Oncol. 2008;26:5783-8. Available from: http://www.ncbi.nlm. nih.gov/pubmed/20045164

54. Chang SC, Lin PC, Yang SH, Wang HS, Liang WY, Lin JK. Taiwan hospitalbased detection of lynch syndrome distinguishes 2 types of microsatellite instabilities in colorectal cancers. Surgery. 2010;147:720-8. Available from: http://dx.doi.org/10.1016/j.surg.2009.10.069

55. Hampel H, Frankel WL, Martin E, Arnold M, Khanduja K, Kuebler P, et al. Screening for the lynch syndrome (hereditary nonpolyposis colorectal cancer). N. Engl. J Med. 2005;352:1851-60. Available from: http://www.ncbi. nlm.nih.gov/pubmed/19038878

56. Erten MZ, Fernandez LP, Ng HK, McKinnon WC, Heald B, Koliba CJ, et al. Universal versus targeted screening for lynch syndrome: comparing ascertainment and costs based on clinical experience. Dig Dis Sci. 2016; Available from: http://www.ncbi.n/m.nih.gov/pubmed/27384051

57. Gould-Suarez M, El-Serag HB, Musher B, Franco LM, Chen GJ. Costeffectiveness and diagnostic effectiveness analyses of multiple algorithms for the diagnosis of lynch syndrome. Dig Dis Sci. 2014;59:2913-26.

58. Pritchard CC, Mateo J, Walsh MF, De Sarkar N, Abida W, Beltran H, et al. Inherited DNA-Repair Gene Mutations in Men with Metastatic Prostate Cancer. N Engl J Med. 2016:NEJMoa1603144. Available from: http://www. nejm.org/doi/10.1056/NEJMoa1603144

59. https://clinicaltrials.gov/. Available from: https://clinicaltrials.gov/. Accessed 1 June 2018.

60. Czink E, Kloor M, Goeppert B, Fröhling S, Uhrig S, Weber TF, et al. Successful immune checkpoint blockade in a patient with advanced stage microsatellite-unstable biliary tract cancer. Mol. Case Stud. 2017;3:a001974. Available from: http://molecularcasestudies.cshlp.org/lookup/doi/10.1101/ mcs.a001974

\section{Ready to submit your research? Choose BMC and benefit from:}

- fast, convenient online submission

- thorough peer review by experienced researchers in your field

- rapid publication on acceptance

- support for research data, including large and complex data types

- gold Open Access which fosters wider collaboration and increased citations

- maximum visibility for your research: over $100 \mathrm{M}$ website views per year

At BMC, research is always in progress.

Learn more biomedcentral.com/submissions 